\title{
Analysis of Social and Environmental Information Reported by American SMEs
}

\author{
Zhen SU \\ Xian-yang Normal University, Xian-yang, Shaanxi, China \\ 463888926@qq.com
}

Keywords: Corporate sustainability reports, SMEs, Inferential statistics.

\begin{abstract}
This paper reports on in-depth empirical study into SMEs in America. It is found, based on descriptive statistics and inferential statistics, that the level of sustainable information reporting of American SMEs is improving, corporate from high-profile industry tend to disclose more sustainable information, and sustainable reports prepared in GRI-form might increase reports' credibility. However, due to the bias of Clarkson et al Scale and the size of sample, a correlation between type of industry, form of reports and the quality of reports cannot be proved.
\end{abstract}

\section{Introduction}

Firms generally regard annual report as a tool by which communicating with various stakeholders. However, its established framework gives fragmentary picture of business activities, as it merely discloses financial information, and precludes non-financial information (Farneti \& Guthrie, 2009). Therefore, sustainability reports, integrating economic, social and environmental performance of a company, are provided to disseminate useful information to stakeholders (Daub, 2007,KPMG, 2008). Nowadays, promoted by scandals of multinational enterprises from developing and developed countries, and increasing global concerns on social and environmental issues, researches on sustainable development of companies are increasing. Among all these studies, some are related to the respect of sustainable development reporting concepts and attempt to define elements influencing the quality of SD reporting, such as agency theory (Ahmed \& Philip, 1989), stakeholder theory (Husillos et al, 2008) and legitimacy theory(Deegan and Gordon, 1996). Some investigate the quality of sustainable development reporting from theoretical and empirical perspectives. For instance, Clarkson et al (2004) demonstrate a negative correlation between sustainability performance and market value. Researches also show that differences in research methods might lead to contradictory findings (Chiara \& Andrea, 2013). Besides, since corporate sustainability reports are kinds of voluntary reports and spreading to different international levels, such as Sustainability Reporting Guidelines from the Global Reporting Initiative (GRI), 'GBS Model' by Italian Group for Studies on Social Reporting and so on. It is not easy to find a suitable reporting framework and to cater various stakeholders' needs. However, an empirical research on Swedish Companies asserts that prepare CSRs according to GRI form might add the credibility of their reports and generate potential gains (Hedberg and Malmborg, 2003). In addition, scholar works state that the incentive for companies to disclose their sustainability information is related positively to environmental sensitive of the industry they belong to (Patten, 1992). For example, Hackston and Milne (1996) assert that companies from high-profile industries tend to disclose more on sustainable development than their peers from Low-profile industry. Cowen et al (1987) point out that consumer-oriented industries tend to disclose more information about their contributions to consumers and to communities, and Dierkes and Preston (1977) proved that extractive industrial companies tend to disclose more on their environmental impacts. Therefore, in order to get a whole picture of the level or quality of disclosure on sustainable development reporting, analyzing social and environmental information reported by companies from different industries, and analyzing CSRs prepared in different forms (i.e. GRI-form or Non-GRI form) are necessary and important.

This paper seeks to describe and discuss the evolution of sustainable development reporting practices of SMEs in America. All information is gathered from their published CSRs, and the 
quality of those selected SMEs' disclosure performances are evaluated by both the quantity of published CSRs and their scores, calculated by Modified Version of Clarkson et al's Scale (2008). Besides, two hypotheses, as follow, are made and tested in this paper

$\mathrm{H}_{01}$ : There is not a significant difference between sustainability reporting quality of reports prepared in different forms.

$\mathrm{H}_{02}$---There is not a significant difference between sustainability reporting quality of different industries.

\section{Design of the Investigation}

The primary purpose of this paper is to give a whole picture of the levels or qualities at which SMEs in America report their sustainable development information. Meanwhile, this paper also tries to portray the evolution of sustainable development reporting of SMEs in America.

All data analysed in this paper are collected and selected from the corporate sustainability reports during 2011 -2014. All the sampled companies are American SMEs listed in the raw-material GRI Database, and all of the selected SMEs are founded since 2010 or earlier.

In this report, two indexes are used to evaluate the quality of American SMEs' reported sustainable information: the quantity of corporate sustainability reports and the quality of these reports. Quantity means how many American SMEs provide corporate sustainability reports (CSRs), the percentage of reports prepared in the GRI-Form, and that of reports prepared in Non-GRI form, while the qualities of published sustainability reports are scored by Modified Version of Clarkson et al's Scale.

Sustainable development reporting involves aligning organizations' offerings with stakeholders' demands, thus, companies become social and environmental responsible as well as meeting their economic expectations (Newson and Deegan, 2002). Thereby, corporate sustainability reports include three aspects: economic, social and environmental information. Up to date, the most popular method used to measure to which level sustainable development is content analysis. However, content analysis owns two limitations: focusing only on quantity of words, sentences or pages, and ignoring the type of reported news (Zegal and Ahmed, 1990). Thereby, Clarkson et al's (2008) design a scoring model. Clarkson's model uses 38 criteria to measure the sustainability reporting quality, and all these 38 items could be classified into four indicators: Disclosure Management Approach (DMA), Environmental Performance Indicators (EPI), Employee and Suppliers Performance Indicators (ESPI) and Community and Consumer Performance Indicators (CCPI), covering all aspects of sustainable development reporting: good news and bad news, 'hard disclosure' and 'soft disclosure', therefore, helping to reduce the potential of self-laudatory. The total scores of each indicator are 11, 49, 66 and 32, respectively. Since scores of some items are spotting from zero to six, whereas, others are either one or zero, therefore, when comparing scores of each category, both absolute figures of score for each indicator and in proportion of each one will be taken into consideration. Both absolute figures and in proportions of each indicator are used to determine the reporting quality.

This paper uses two methodologies. The first one is descriptive statistics (mean, standard deviation, maximum of the score) and serves to portray the outline of sustainable development reporting of SMEs in America. The second one is statistical-inferential which studies the correlation between the disclosure quality and the influence factors, such as types of industry and forms of reports prepared. The correlation can be studied by using independent sample T-test and Pearson correlation coefficient. When using independent sample T-test, we first assume the means of two populations are equal, and then calculate the $\mathrm{T}$ value by the formula 1 , 


$$
\begin{aligned}
& t=\frac{\bar{x}-\bar{y}}{\sqrt{s^{2}\left(\frac{1}{n_{1}}+\frac{1}{n_{2}}\right)}} \sim t\left(n_{1}+n_{2}-2\right) \\
& s^{2}=\frac{\left(n_{1}-1\right) s_{1}^{2}+\left(n_{2}-1\right) s_{2}^{2}}{n_{1}+n_{2}-2}
\end{aligned}
$$

$$
\frac{\sum\left(x_{i}-\bar{x}\right)\left(y_{i}-\bar{y}\right)}{\sqrt{\sum\left(x_{i}-\bar{x}\right)^{2}} \sqrt{\sum\left(y_{i}-\bar{y}\right)^{2}}}
$$

While $\bar{x}, \bar{y}$ are sample mean, $n_{1}, n_{2}$ are the sample size, $s_{1}^{2}, s_{2}^{2}$ are the sample variance. At last, draw a conclusion by compare the $\mathrm{T}$ value and critical value. When calculate the Pearson correlation coefficient, we use the formula 2,

\section{Data Description and Discussion}

With respect to the number of sustainable reports provided, it is not hard to find that the reporting level has been improved during the four years. In 2011, only 15 SMEs provided sustainability reports, accounting for about $24.2 \%$ of the total sampled SMEs. On contrary, in 2014, the number of American SMEs providing sustainability reports doubled (31), accounting for 50\%. Besides, the quality of corporate sustainability reports, measured by scores, also improves. Its average score is increasing slightly, from 31.13 (2011) to 34.84 (2014). Its mean score grows too, from 31 (2011) to 35 (2014). Of all selected sample, the maximum score is 79, appearing in 2014, while the lowest score is 11, appearing in 2011.

After calculating the average score of each company year by year, we get the Company-level disclosure. The average scores of sampled companies calculated by Clarkson et al Scale vary from 11 to 79. An interesting phenomenon is that two of the three companies with the highest scores of sustainable development reporting are companies from high-profile industry, and two out of the three companies with lowest scores are companies which provide Non-GRI Form sustainability reports. Moreover, the most qualified CSR is prepared in Non-GRI form by a low-profile industrial company, and the worst qualified CSR is prepared in GRI-Form by a high-profile industrial company from.

In aspect of absolute figures, almost all the scores for the four indicators witness gradual rises, except for CCPI, fluctuating around 5.50. EPI Category is scored highest, increasing by 1.86, from 17.27 to 19.13 . Followed by are Category ESPI (from 6.8 to 6.97), Category CCPI (spotting about 5.50) and Category DMA (ranging from 2.6 to 2.77). In aspect of proportion for each category, that of Category EPI rose up moderately, from $35.24 \%$ to $39.04 \%$. In contrary, the percentage of Category CCPI bottomed to $15.75 \%$ in 2013 , after then climbed up to $17.25 \%$ in 2014 , increasing by $2.75 \%$ (compared with that in 2011). The proportion of the rest two categories named DMA and ESPI remained constantly at $25 \%$ and $10 \%$, respectively. It is noted that SMEs in America are prone to disclose more on environmental information, as both the absolute figures and percentage of Category EPI account for the largest position. This phenomenon is corresponded to the concurrent increase in environment disclosures and membership of environmental groups in America (Deegan and Gordon, 1996, Diana et al, 2015). While, the last thing American SMEs disclose is the sustainable development of their employees' and suppliers' welfare. Interestingly, differ from other three indicators, CCPI dropped by 0.88 by absolute figure and by $2.75 \%$ by proportion. And the reason might be explained by different level of pressures from their stakeholders, and the reporting cost. Perhaps, stakeholder theory and agency theory might be helpful to explore such problem.

When measuring disclosure quality of SMEs from different types of industry from the perspective of quantity level, something interesting could be found. All SMEs (18) from high-profile industry provide corporate sustainability reports, whereas, only 25 out of 44 SMEs from low-profiled industry provide corporate sustainability reports. The average number of corporate sustainability reports provided by high-profile industry SMEs is about 0.85 per company per year, while that for low-profiled industry SMEs is about 0.21 per company per year. In aspect of quantity, the disclosure quality of SMEs from high-profile industry is much higher than that of SMEs from low-profile industry. Besides, $80 \%$ of the top 5 sustainable development information 
producers come from high-profile industry, 80\% of the top 5 environmental information producers belong to extractive industry, and $80 \%$ of community and consumer related information producer are SMEs from consumer-orientation industry. The mean value of scores for high profile industry is 34.72, larger than that of score for Low profile industry. Therefore, it is implicated that the quality of sustainable reporting of corporate from high profile industry is higher than that of corporate from low profile industry.

All data seems to prove the conclusion that disclosure quality is influenced by the reporting form and the type of industry. GRI-Form reports is more creditable than their Non GRI form peers (Moore, 2012; KPMG, 2013; Deegan and Gordon, 1996), and corporate from higher-profile industry tend to disclose more sustainable development information. However, before getting the final conclusion, some hypotheses need to be tested.

The first Null Hypothesis

$\mathrm{H}_{01}$ : There is not significant difference in sustainability reporting quality of reports prepared in different forms.

Since the Sig-Value and T-Value for H01 are 0.194 and 1.322, respectively, therefore, the null hypothesis H01 should not be rejected. Therefore, the forms in which the corporate sustainability reports are prepared do not influence the quality of sustainable development reporting. Therefore, higher score for reports prepared in GRI-Form should be attributed to other reasons, or this is just a coincidence. Meanwhile, the Pearson correlation test between the reporting quality and the reports form has also be done. The Pearson correlation test shows that Pearson correlation coefficient between the reporting quality and the reports form is 0.210 , Sig value is 0.194 , which means the null hypothesis is not rejected. It is proved again that the reporting quality is uncorrelated with the reports form.Although compared to Non-GRI form reports, GRI-form reports seem to get higher average score, however, the first null hypothesis is not be rejected, as there is no enough statistic evidence to prove strongly the correlations between reporting quality and form of reports. This might be explained the implicit bias of Clarkson et al Scale. Since this Model is extended from GRI reporting framework, therefore, GRI form reports are likely to contain more items than Non-GRI form reports, therefore, get higher scores. However, some Non-GRI form reports are also scored higher; for example, CSR prepared by Traditional Medicinals is Non-GRI form reports, it is scored the highest among all selected samples. On contrary, Curtis Packaging prepared its CSR in GRI-form; however, it is scored at 11, lower than other companies, either preparing reports in GRI-form or Non-GRI form. Besides, factors like the amount of sample selected, the producers' preference etc. might attribute to such result.

The second null hypothesis:

$\mathrm{H}_{02}$---There is not significant difference between sustainability reporting quality of different industries.

The result of this test shows that the Sig-Value and T-Value for H02 are 0.404 and -0.844 , respectively. Statistically, the significant variation has not been found in the mean disclosure scores and as a result, the null hypothesis should not be rejectted. Therefore, to which level the sustainability information reported is not associated with the type of industry. Meanwhile, the Pearson correlation test between the reporting quality and the type of industry is done. The result is shown in Table 1.20 shows that Pearson correlation coefficient between the reporting quality and the type of industry is -0.137 , Sig value is 0.404 , which means there is no strong statistic evidence to reject the null hypothesis. It is proved again that the reporting quality is uncorrelated with the type of industry.

Compared to reports of low-profile industry, that of high-profile industry get a higher average score, that is to say, the reporting quality of high-profile industry is higher than that of their peers form low-profile industry. In addition, scores of each report seems to prove prior researches that the incentive for companies to disclose their environmental information is positively related to their environmental sensitive (Patten, 1992). However, result of the second hypothesis cannot prove strongly that there is correlation between reporting quality and type of industries. This might be explained by company's self-laudatory nature. Although, driven by stakeholders' pressure, 
high-profile companies disclose more information than their low-profile peers, they still tend to disclose little or no information associated with bad news, as a result, the scores measured by Clarkson et al Scale is low, this is because most of items could be scored from zero to six. Therefore, such high-profile companies still get lower scores, and similarly, low-profile companies which do not influence environment negatively might disclose more on their sustainable development, and get relative higher scores.

\section{Summary}

This report presents an empirical investigation into the quality of sustainable development reporting of sampled SMEs in America. During the past four years, 2011-2014, an increasing number of American SMEs provide corporate sustainability reports, and the quality of sustainable development reporting is improving. In a word, American SMEs are showing increasing concerns on sustainable development reporting. However, problems still exist in the field of reporting quality, loads of useful sustainable information are not be reported or reported little in CSRs, this might be explained by lack of mandatory provisions, the proportion of report prepared in GRI-Form remains constant at poor levels. In conclusion, little improvement is made in the field of reporting quality during the four years. SMEs in America need to disclose more useful sustainable development information and disclose such information in comparative forms.

The disclosure quality varies among different categories, under the pressure form environmental regulations and policies, SMEs in America are prone to disclose more on environmental information, but report little about human right.

This report also examined correlations between reporting quality and industry types, however, lack enough statistic evidence to support prior studies that reporting qualification is correlated to industry type. This might be explained by the small size of selected sample in this report.

Besides, according to data selected and collected, it is not clearly to investigate which one, reporting form or type of industry, does really influence the reporting quality. This is because $2 / 3$ high-profile SMEs provide GRI-form reports, and 60\% low-profile ones provide Non-GRI form reports. Therefore, in order to make sure which factor does really effect the reporting quality, an regression test between reporting quality and reporting form , type of industry would be made in future studies and to make sure whether it is necessary to make GRI-form mandatory to improve SMEs sustainable development reporting quality.

\section{Reference}

[1]Ahmed Belkaoui and Philip G. Karpik, (1989), Determinants of the Corporate Decision to Disclose Social Information, Accounting, Auditing \& Accountability Journal, Vol. 2 pp: 282-311.

[2]Cowen, S. S, Ferreri, L. B., \& Parker, L. D. (1987), The impact of corporate characteristics on social responsibility disclosure: A typology and frequency-base analysis. Accounting, Organizations and Society,12, 111-122

[3]Chiara Mio and Andrea Venturelli, (2013), Non-financial Information about Sustainable Development and Environmental Policy in the Annual Reports of Listed Companies: Evidence from Italy and the UK, Corporate Social Responsibility and Environmental Management Corp. Soc. Responsibility. Environ. Mgmt. 20, pp: 340-358

[4]Clarkson P, Li Y, Richardson G, (2004), The market valuation of environmental expenditures by pulp and paper companies, The Accounting Review, 79, PP: 329-353.,

[5]Clarkson P, Li, Y., Richardson, G. and Vasvari. F. (2008), Revisiting the relation between environmental performance and environmental disclosure: An empirical analysis, Accounting, Organizations and society 33(4), 303-327.

[6]Daub, C.H. (2007), Assessing the quality of sustainability reporting: An alternative 
methodological approach. , Journal of Cleaner Production, 15, 75-85.

[7]Dierkes, M. and Preston, L.E. (1977), Corporate social accounting and reporting for the physical environment: a critical review and implementation proposal, Accounting, Organizations and Society, Vol. 2 No. 1, pp. 3-22.

[8]Diana-Maria Tinjala, Lavinia Mirela Pantea and Alexandru Buglea, (2015),2010-2014: A Comparative Evolution of Sustainability Reporting and its Assurance in Europe and the USA, Timisoara Journal of Economics and Business, Volume 8, pp 48-69,

Deegan, C and Gordon, B. (1996), A Study of the Environmental Disclosure Practices of Australian Corporations, Accounting and Business Research, 26, 187-199

[9] Hackston, D. and Milne, M. J. (1996), Some determinants of social and environmental disclosures in New Zealand companies. Accounting, Auditing \& Accountability Journal, 9, 77-10

[10]Hedberg C.J. and Malmborg F. V, (2003), The Global Reporting Initiative and Corporate Sustainability Reporting in Swedish Companies, Corporate Social Responsibility and Environmental Management, 10, pp 153-164

[11]Husillos, Javier, Alvrezgil, Mariaj, (2008), A Stakeholder Theory Approach Take-holder Theory Approach to Environmental Disclosures by Small and Medium Enterprises (SMEs), Revista de Contabilidad, vol. 11, núm. 1, 2008, pp. 125-156,

[12]KPMG, (2008), KPMG International Survey of Corporate Responsibility Reporting 2008, KPMG International: The Netherlands.

[13]KPMG, (2013), The KPMG survey of corporate responsibility reporting

[14]Moore, W, (2012), Sustainability reporting: A work in progress. Journal of Sustainability and Green Business

[16]Newson, M. and Deegan, C, (2002), Global expectations and their association with corporate social disclosure practices in Australia, Singapore, and South Korea, The International Journal of Accounting, 37, 183-213

[17]Patten, D.M. (1992),'Intra-industry Environmental Disclosures in Response to the Alaskan Oil Spill: A Note on Legitimacy Theory', Accounting, Organizations and Society, Vol.15, No. 5, pp. 471-75.

[18]Zegal, D. and Ahmed, S.A., (1990), Comparison of Social Responsibility Information Disclosure Media Used by Canadian Firms, Accounting, Auditing and Accountability Journal, 3, pp. 38-53 